\title{
Quantitative proteomics identification of phosphoglycerate mutase 1 as a novel therapeutic target in hepatocellular carcinoma
}

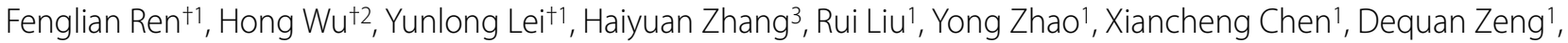 \\ Aiping Tong ${ }^{1}$, Lijuan Chen ${ }^{1}$, Yuquan Wei ${ }^{1}$ and Canhua Huang*1
}

\begin{abstract}
Background: Hepatocellular carcinoma (HCC) is one of the most common malignancies worldwide with poor prognosis due to resistance to conventional chemotherapy and limited efficacy of radiotherapy. There is an urgent need to develop novel biomarkers for early diagnosis, as well as to identify new drug targets for therapeutic interventions.

Patients and methods: 54 paired HCC samples and 21 normal liver tissues were obtained from West China Hospital of Sichuan University. Informed consent was obtained from all the patients or their relatives prior to analysis, and the project was approved by the Institutional Ethics Committee of Sichuan University. Stable Isotope Labeling with Amino Acids in Cell Culture (SILAC)-based proteomics was employed to profile the differentially expressed proteins between a HepG2 human hepatoma cell line and an immortal hepatic cell line L02. Validation of PGAM1 expression was performed by semi-quantitative RT-PCR, immunoblot and immunohistochemistry using clinical samples. shRNA expressing plasmids specifically targeting PGAM1 were designed and constructed by GenePharma Corporation (Shanghai, China), and were utilized to silence expression of PGAM1 in vitro and in vivo. Cell proliferation was measured by a combination of colony formation assay and Ki67 staining. Apoptosis was examined by flow cytometry and TUNEL assay.

Results: A total of 63 dysregulated proteins were identified, including 51 up-regulated proteins, and 12 downregulated proteins (over 2-fold, $p<0.01$ ). Phosphoglycerate mutase 1 (PGAM1) was found markedly upregulated. Clinico-pathological analysis indicated that overexpression of PGAM1 was associated with $66.7 \% \mathrm{HCC}$, and strongly correlated with poor differentiation and decreased survival rates $(p<0.01)$. shRNAs-mediated repression of PGAM1 expression resulted in significant inhibition in liver cancer cell growth both in vitro and in vivo.
\end{abstract}

Conclusion: Our studies suggested that PGAM1 plays an important role in hepatocarcinogenesis, and should be a potential diagnostic biomarker, as well as an attractive therapeutic target for hepatocellular carcinoma.

\section{Background}

Hepatocellular carcinoma (HCC) is the fifth most common malignancy worldwide with poor prognosis, and is responsible for 600000 deaths annually worldwide [1-5]. Many patients are diagnosed at the advanced stage and missed the best opportunity for effective therapy, such as liver resection, or transplantation. On the other hand,

\footnotetext{
*Correspondence: hcanhua@scu.edu.cn

1 The State Key Laboratory of Biotherapy, West China Hospital, Sichuan University, Chengdu, 610041, China

+ Contributed equally

Full list of author information is available at the end of the article
}

patients who were resected often have a high frequency of metastasis/recurrence, and postoperative 5-year survival is only $30 \%-40 \%$ [6]. Moreover, liver transplantation is not applicable universally because of the shortage of organ donations and occurrence of relapse [7]. Consequently, there is an urgent need to screen for novel therapeutic targets.

The metabolism of cancer cells differs significantly from that of normal cells [8]. Cancer cells are able to maintain high rates of aerobic glycolysis even under the high-oxygen $(20 \%)$ conditions of normal tissue culture. 
This property, known as the "Warburg effect", has been recognized for over 70 years $[9,10]$. In this context, maintaining a high level of glycolysis is indispensable for survival and growth of cancer cells [11]. Guided by this principle, intervention with cellular glucose utilization could lead to a significant inhibition of cell growth, induction of cell death, stimulating migration of key enzymes out of the glycolytic enzyme complexes as well $[12,13]$. Recently, chemistry-based functional proteomics was applied to screen for drug target against breast cancer, and phosphoglycerate mutase 1 (PGAM1) was identified as a novel metabolic enzyme involved in breast carcinogenesis [14].

In adult mammals, three isozymes of PGAM are present which result from the homo- and heterodimeric combinations of two different $30-\mathrm{kD}$ subunits, $\mathrm{M}$ and $\mathrm{B}$, encoded by two different genes $[15,16]$. The homodimer BB-PGAM (a brain form; PGAM1 in human), is expressed mainly in liver, kidney, and brain; the homodimer MM-PGAM (muscle-specific form; PGAM2 in human), is mainly found in the mature muscle cells; and the heterodimer MB-PGAM, mainly exists in heart [1618]. Particularly, PGAM1, a key enzyme of the glycolytic pathway, converts 3-phosphoglycerate to 2-phosphoglycerate with 2, 3-bisphosphoglycerate (2, 3-BPG) as a cofactor of the reaction to release energy which is essential for cell growth [19]. Several investigations demonstrated that PGAM1 was overexpressed in a variety of human cancers, including breast carcinoma [14,20]; colorectal cancer [21,22]; lung cancer [23,24]; prostate cancer [19]; oral squamous cell carcinoma [25]; esophageal squamous cell carcinomas [26]; and also associated with certain virus infection $[27,28]$. Overexpression of PGAM1 can immortalize mouse embryonic fibroblasts and promote cell proliferation, suggesting its potential oncogenic property
[10]. Furthermore, a recent study showed that a PGAM1 peptide inhibitor induced cancer cell growth arrest in breast carcinoma [14]. Taken together, targeting the PGAM1 may be preferentially lethal to the malignant cells and have potentially broad clinical and therapeutic implications.

In the present study, we utilized a quantitative proteomic approach to profile the altered expressed proteins between a liver cancer cell line HepG2, and an immortalized human normal hepatocyte cell line L02. Of the 63 dysregulated proteins, we found that PGAM1 was significantly upregulated. Clinicopathological analyses revealed that overexpression of PGAM1 was closely associated with hepatocarcinogenesis. The data presented in this study suggested that PGAM1 could be developed as a useful diagnostic biomarker, as well as a potential therapeutic target for hepatocellular carcinoma.

\section{Experimental Procedures}

\section{Clinical specimens}

Paraffin-embedded HCC and the adjacent normal tissues were obtained from 54 patients who underwent surgical resections at the West China Hospital of Sichuan University (Chengdu, China). Histodifferentiation grading of specimens was assigned according to Edmondson Steiner grading by experienced pathologists. 21 normal liver specimens were collected from patients undergoing surgical resections for hepatic cyst or calculus of intrahepatic duct. The surgical pathologic staging was assigned according to the modified UICC classification [29]. A summary of detailed clinicopathologic information for these patients was shown in Table 1. Each tissue was cut into two parts: one part was snap frozen for immunoblot and RT-PCR validation, and the other part was fixed in formalin for immunohistochemistry analysis. Informed

\section{Table 1: Clinicopathologic features of all patients.}

\begin{tabular}{lcc}
\hline Clinicopathologic Features & Number & Mean Agea(\%) \\
\hline Normal liver tissues & 21 & $45.4 \pm 5.7$ \\
Hepatocellular carcinoma & 54 & $44.8 \pm 8.5(100.0)$ \\
Histodifferentiation grading & & $45.2(20.4)$ \\
Well differentiated & 11 & $40.6(51.9)$ \\
Moderately differentiated & 28 & $46.4(27.8)$ \\
Poorly differentiated & 15 & $48.1(25.9)$ \\
Surgical pathologic staging & & $43.9(38.9)$ \\
I & 14 & $46.1(16.7)$ \\
II & 21 & $45.3(18.5)$ \\
III & 9 & 10 \\
IV
\end{tabular}

a Mean age in years. 
consent was obtained from all the patients or their relatives prior to analysis, and the project was approved by the Institutional Ethics Committee of Sichuan University.

\section{Cell culture, SILAC labeling and transfection}

Human hepatoma cell line HepG2 was purchased from ATCC (Rockville, MD, USA) and maintained in Dulbecco's modified Eagle's medium (DMEM, Gibco, USA) supplemented with $10 \%$ fetal calf serum (Hyclone, USA), penicillin $\left(10^{7} \mathrm{U} / \mathrm{L}\right)$ and streptomycin $(10 \mathrm{mg} / \mathrm{L})$ at $37^{\circ} \mathrm{C}$ in a $5 \% \mathrm{CO}_{2}$ atmosphere. Human immortalized normal liver cell line L02 was obtained from China Cell Culture Center (Shanghai, China) and cultured in Dulbecco's modified Eagle's medium (DMEM, Gibco, USA) [30].

For SILAC-labelling, cells were grown in SILAC ${ }^{\mathrm{TM}} \mathrm{D}$ MEM (Invitrogen, USA) containing 10\% v/v dialysed FBS, $2 \mathrm{mM}$ L-glutamine, and either $0.1 \mathrm{mg} / \mathrm{mL}$ SILAC $^{\mathrm{TM}}$ light $\left[{ }^{12} C_{6}\right]$ or SILAC ${ }^{\mathrm{m} M}$ heavy $\left[{ }^{13} \mathrm{C}_{6}\right]$ L-lysine (Invitrogen). To ensure full incorporation of the heavy and light labeled amino acids, cells were grown for at least six cell doublings prior to analysis.

For transient transfection, HepG2 cells were seeded in 6- or 96-well culture plates at a density of $10^{5}$ cells or 5000 cells/well, respectively. After incubated overnight, cells were transfected with PGAM1-shRNA ( $2 \mu \mathrm{g} /$ well) or the scramble shRNA using Lipofectamine 2000 (Invitrogen, Carlsbad, CA) according to the manufacturer's instructions.

\section{Protein preparation and SDS-PAGE separation}

Equal amounts of protein from HepG2 $\left({ }^{13} \mathrm{C}_{6}\right.$-lysine) and L02 $\left({ }^{12} \mathrm{C}_{6}\right.$-lysine) cell lines were mixed (60 $\mu \mathrm{g}$ in total), boiled in SDS-PAGE sample buffer, resolved by SDSPAGE and stained with Coomassie Brilliant Blue R-250 (Merck, Germany).

\section{In-gel trypsin digestion}

In-gel digestion was performed using mass spectrometry grade Trypsin Gold (Promega, Madison, WI, USA) according to the manufacturer's instructions. Briefly, the excised gel slices were destained twice with $100 \mathrm{mM}$ $\mathrm{NH}_{4} \mathrm{HCO}_{3} / 50 \%$ acetonitrile at $37^{\circ} \mathrm{C}$ for $45 \mathrm{~min}$, and dried in a centrifugal vacuum concentrator, followed by a preincubation in 10-20 $\mu$ trypsin solution for $1 \mathrm{~h}$. Subsequently the digestion buffer were added (40 mM $\mathrm{NH}_{4} \mathrm{HCO}_{3} / 10 \% \mathrm{ACN}$ ) to cover the gel pieces and incubated overnight at $37^{\circ} \mathrm{C}$. Tryptic digests were extracted twice with $50 \% \mathrm{ACN} / 5 \%$ trifluoroacetic acid (TFA) for 1 $\mathrm{h}$ each time. The combined extracts were dried in a vacuum concentrator to a final volume of $5 \mu \mathrm{l}$ at room temperature. The samples were then subjected to mass spectrometric analysis.

\section{Protein identification and quantitation by LC-MS/MS}

Mass spectra were acquired using a LC-MS mass spectrometer (Micromass, Manchester, UK). Tryptic digests were dissolved in $20 \mu \mathrm{l}$ of $50 \% \mathrm{ACN}$. The automatic scan rate was $1.0 \mathrm{~s}$ with an interscan delay of $0.02 \mathrm{~s}$, and the voltage was operated at $3.0 \mathrm{KV}$. Spectra were accumulated until a satisfactory signal/noise ratio had been obtained with the range $400-1600 \mathrm{~m} / \mathrm{z}$ picked out for LC-MS/MS analysis. The collision energy was varied between 18 - $57 \mathrm{eV}$ depending on the mass of the precursor. Quantitation was carried out by SILCA K+ $6 \mathrm{R}+10$ [MD]. The MS/MS data, "pkl list" files were acquired by the software ProteinLynx 2.2.5 software (Waters), which include the mass values, the intensity and the charge of the precursor ions (parent ions with $+1,+2$ or +3 charges in this study). The pkl files were analyzed using the MASCOT search engine against the Swiss-Prot protein database. The search parameters were carried out as follows: Database, Swiss-Prot; taxonomy, homo sapien; enzyme, trypsin; and an allowance of one missed cleavage. Carbamidomethylation was set as a fixed modification and oxidation of methionine was variable. The peptide and fragment mass tolerance were both set at $0.2 \mathrm{Da}$. Proteins were identified at least one peptide exceeding their score threshold $(p<0.01)$ and with their MW and pI consistent with the gel regions from which the bands were excised indicated the $95 \%$ confidence level for the matched peptides. Protein intensity alteration ( $>2$ fold) was defined as dysregulation.

\section{Semi-quantitative RT-PCR}

The following primer sequences were used to detect PGAM1 transcripts: sense (5'-GCACCCACTCCCTTCATACAAT-3') and antisense (5'-ACGCAGGTTACATTCGTCTTCC-3'). Total RNA was extracted using Trizol Reagent (Invitrogen, USA). RT-PCR reaction was performed as follows: reverse transcription at $45^{\circ} \mathrm{C}$ for 30 min and denaturation at $94^{\circ} \mathrm{C}$ for $2 \mathrm{~min}$; then amplification for 30 cycles at $94^{\circ} \mathrm{C}$ for $30 \mathrm{~s}$, annealing at $54^{\circ} \mathrm{C}$ for 1 min, and extension at $72^{\circ} \mathrm{C}$ for $1.5 \mathrm{~min}$, followed by a terminal elongation step at $72^{\circ} \mathrm{C}$ for $10 \mathrm{~min}$ and a final holding stage at $4^{\circ} \mathrm{C}$. PCR products were resolved by $1 \%$ agarose gel electrophoresis.

\section{Western blotting analysis}

Western blotting analysis was performed as described elsewhere [31]. Briefly, $30 \mu \mathrm{g}$ of proteins were separated by $12 \%$ SDS-PAGE and transferred to PVDF membranes (Amersham Biosciences). After blocking overnight with TBS/T containing $0.1 \%$ Tween 20 in $5 \%$ skimmed milk at $4^{\circ} \mathrm{C}$, the membranes was subsequently probed with primary antibody PGAM1 (diluted 1:1000, Abcam) for $2 \mathrm{~h}$ at RT and washed 3 times in TBS/T. Subsequently the membranes were incubated with secondary antibody conju- 
gated to Horseradish Peroxidase for $2 \mathrm{~h}$ at RT. Immunoblot was detected by the enhanced chemiluminescence (ECL) detection system (Pierce Biotech Inc., Rockford, IL, USA).

\section{Immunohistochemistry analysis}

Tissues were formalin-fixed and Paraffin-embedded, and sections were consecutively cut into 3-4 $\mu \mathrm{m}$ thickness for immunohistochemistry (IHC) analysis using a Dako EnVision System (Dako Cytomation GmbH, Hamburg, Germany Denmark) according to the manufacturer's instructions. Briefly, the paraffin-sections were dewaxed, rehydrated, and incubated in $3 \% \mathrm{H}_{2} \mathrm{O}_{2}$ for 10 min in dark at room temperature to quench the endogenous peroxidase activity. Antigen retrieval was performed in citrate buffer (pH 6.0) using autoclave sterilizer method. Subsequently, the sections were blocked by normal rabbit or goat serum diluted in PBS ( $\mathrm{pH} \mathrm{7.4)}$ ) for $20 \mathrm{~min}$ at $37^{\circ} \mathrm{C}$, followed by an incubation at $4^{\circ} \mathrm{C}$ overnight with the primary antibodies, either goat anti-PGAM1 (diluted 1:150, Abcam, Cambridge, UK) or mouse anti-Ki67 (diluted 1:200, Santa Cruz Biotechnology, Santa Cruz, CA). After rinse in fresh PBS for 15 min, slides were incubated with horseradish peroxidase-linked rabbit anti-goat and antimouse antibodies at $37^{\circ} \mathrm{C}$ for $40 \mathrm{~min}$, followed by reaction with 3,3'-diaminobenzidine substrate solution (Dako Cytomation $\mathrm{GmbH}$ ) and counterstaining with Mayer's hematoxylin. The immunohistochemical staining was assessed by calculating the percentage of positive hepatocytes and the immunostaining intensity [32]. Slides were examined separately by two independent pathologists with no prior knowledge of each patient's clinical and pathological parameters. Any discrepancy between the two evaluators was resolved by reevaluation and careful discussion until agreement was reached.

\section{Cell proliferation and apoptosis assay}

Upon treatment, cells were incubated at $37^{\circ} \mathrm{C}$ for indicated durations. Cell proliferation was measured by means of MTT assay according to the manufacturer's instructions. $20 \mu \mathrm{l} \mathrm{MTT} \mathrm{(} 2 \mathrm{mg} / \mathrm{ml}$, Sigma, St. Louis, MO) was added in the media and incubated for another $2 \mathrm{~h}$. The media was removed and formazan precipitate was dissolved in $150 \mu$ l Dimethyl Sulfoxide (DMSO, Amresco, Solon, Ohio, USA). Ten minutes later, absorbance values were measured at $595 \mathrm{~nm}$ wavelength on a Spectra Max M5 (MDC, Sunnyrale, VA, USA).

For colony formation assay, cells were seeded in 6-well plates at a density of 300 cells per well. Assay was performed at $24 \mathrm{~h}$ posttransfection, cells were cultured for another two weeks. Colonies were washed with PBS, fixed with methanol and stained with Crystal Violet (Sigma, St. Louis, MO, USA). Cells were counted under a microscope and a cluster with more than 50 cells was considered as a clone.

For flow cytometric analysis, cells were trypsinized and washed with $0.9 \% \mathrm{NaCl}$ at $72 \mathrm{~h}$ post transfection, and then fixed with $70 \%$ ethanol at $4^{\circ} \mathrm{C}$ overnight. Cells were incubated with staining solution $(5 \mu \mathrm{g} / \mathrm{ml}$ propidium iodide, $20 \mu \mathrm{g} / \mathrm{ml}$ Rnase A) in dark at room temprature for $1 \mathrm{~h}$. The stained cells were analyzed on an EPICS ELITE ESP flow cytometer (Beckman Coulter, USA).

TUNEL staining was performed using terminal deoxynucleotidyl transferase (Promega Inc., Madison, WI, USA). Cells were fixed in freshly prepared $4 \%$ methanolfree formaldehyde solution in PBS (pH 7.4) for 25 minutes at $4^{\circ} \mathrm{C}$, washed with fresh PBS for 10 minutes at room temperature and permeabilized in $0.2 \%$ Triton- 100 solution in PBS for another $5 \mathrm{~min}$. After equilibration for $10 \mathrm{~min}$, the cells were incubated with $\mathrm{rTdT}$ buffer and observed under a fluorescence microscope, and a nucleus with bright green fluorescence staining was recorded as a TUNEL-positive event (Olympus Optical Co, Hamburg, Germany).

\section{Tumor xenograft model and shRNA treatment}

The cDNA sequence of PGAM1 was obtained from Genbank (NM 002629). Three PGAM1-specific short hairpin RNAs (shRNAs) were designed based on the rules as described elsewhere [33]. As shown in Table S1, additional file 1, shRNA expressing plasmids specifically targeting PGAM1 (termed as PGAM1-shRNA-a, -b and -c) were constructed by GenePharma Corporation (Shanghai, China) using pGPU6/GFP/Neo vector. An unrelated shRNA sequence (HK), with no homology to any human gene, was used as a negative control (shNC).

For animal study, 6-8 weeks old female nude mice (BALB/c, 18-20 g body weight) were injected subcutaneously with HepG2 cell suspensions about $2 \times 10^{6}$ cells/100 $\mu \mathrm{l} /$ mouse in PBS via the right flank. When the tumor diameter reached about $6 \mathrm{~mm}$, the tumor-bearing mice were randomly divided into four experimental groups (n = 5 mice/group): 1) PBS: $100 \mu \mathrm{l} /$ mouse; 2) LIPO: Lipofectamine 2000 at $12.5 \mu \mathrm{l} / 100 \mu \mathrm{l}$ of PBS; 3) shNC (negative control): $5 \mu \mathrm{g} / 100 \mu \mathrm{l}$ of PBS; 4) PGAM1-shRNA-a: 5 $\mu \mathrm{g} / 100 \mu \mathrm{l}$ of PBS. Tail intravenous injections were performed every two days, and the tumor volumes were evaluated by the following formula: tumor volumes $\left(\mathrm{mm}^{3}\right)=\pi / 6 \times$ length $\times$ width $^{2}$. The tumor growth inhibition in the presence or absence of PGAM1 shRNA has been monitored for 20 days until the mice were sacrificed. The tumor tissues were formalin-fixed and paraffin-embedded for immunohistochemistry. All animals received humane care according to the Institutional Animal Care and Treatment Committee of Sichuan University. 


\section{Statistics}

All quantitative data were recorded as mean \pm S.D. Comparisons between two groups were performed by Student's $t$ test. Differences among multiple groups were assessed by one-way ANOVA analysis, LSD- $t$ test. Relevance analysis of ordinal data was performed by cross $X^{2}$ test. Statistical significance was defined as $p<0.05$.

\section{Results}

Proteomic profiling of the differentially expressed proteins between HepG2 and LO2 by SILAC

Differentially expressed proteins were defined as statistically significant based on two criteria: 1) intensity alterations $>2.0$-fold (Student's $t$ test, $p<0.05$ ) and 2) recurrence more than two times in the 3 repeated experiments. According to these criteria, a total of 63 distinct proteins were identified by LC-MS/MS, as listed in Table 2. Cluster analysis revealed that the altered proteins were involved in diverse biological processes, including metabolism (34.9\%), signal transduction (12.7\%), structural component (7.9\%) and others (44.5\%) (Fig. 1A and 1B). Among them, PGAM1 was identified with most significant alteration that PGAM1 was up-regulated over 6-fold in HepG2 cells compared to L02 cells $(p<0.01)$. Further, LC MS/MS analysis revealed eight matched peptides, with 38\% sequence coverage and a MOWSE score of 172 (Fig. 1, C-F). The housekeeping gene $\beta$-actin was always selected to monitor the labeling status.

\section{Overexpression of PGAM1 in HCC}

To examine if PGAM1 was overexpressed in $\mathrm{HCC}$, a validation experiment was carried out. A total of 54 paired liver cancer tissues were collected, and expression of PGAM1 was compared at both transcriptional and translational levels between HCC tissues and the corresponding adjacent noncancerous tissues. As shown in Fig. 2A, the transcripts of PGAM1 were much higher in $\mathrm{HCC}$, compared with the noncancerous tissues. Further immunoblot analysis was performed using anti-PGAM1 antibody, and overexpression of PGAM1 was observed in $66.7 \%(36 / 54)$ of the HCC tissues (Student's $t$ test, $p<$ 0.01). Together, our data demonstrated that PGAM1 is overexpressed in $\mathrm{HCC}$ tissues at both mRNA and protein levels, which is consistent with the observation in the quantitative proteomic analysis (Fig. 2B and 2C).

\section{Overexpression of PGAM1 was correlated with poor prognosis of HCC}

To further investigate the potential oncogenic properties of PGAM1 in hepatocarcinogenesis, immunohistochemistry was performed to examine PGAM1 expression in paraffin-embedded tissues. 54 pairs of HCC tissues at different clinicopathologic stages and 21 normal liver tissues were prepared for immunohistochemical analysis. Of the
54 HCC samples (mean age, $44.8 \pm 8.5$ years), 11 were well differentiated, 28 were moderately differentiated, and 15 were poorly differentiated; 14 were in staging I, 21 were in staging II, 9 were in staging III, and 10 were in staging IV according to Surgical Pathologic Staging Criteria (6th Edition, 2002) (Table 1). In 54 paired HCC samples, no or weakly positive staining could be detected in 19 and $81 \%$ of non-tumor liver tissues, respectively (Table 3 ). By contrast, in tumor tissues, weakly positive staining was observed in $24 \%(13 / 54)$, moderately positive staining was about $35 \%(19 / 54)$ and the strong positive staining was $41 \%(22 / 54)$ (Table 4$)$. As shown in Fig. 3A, the staining intensity and the number of positively stained cells were markedly different between normal and hepatoma tissues $(p<0.01)$. Overexpression of PGAM1 was more likely to be present with poor differentiation $(p<$ $0.05)$.

To assess the correlation between overexpression of PGAM1 and the survival rates, 54 patients were retrospectively studied (Fig. 3B). The five year survival rates were $55.6 \%, 28.6 \%, 18.2 \%$ for weakly positive, positive and strongly positive staining samples, respectively. In order to evaluate whether PGAM1 could be utilized as an independent prognostic factor associated with clinical outcome of HCCF, multivariate analyses were carried out using Cox proportional hazard model. The risk variables examined included PGAM1 immunoreactivity (weakly/ moderately compared with strongly positive), age of patients ( $>50$ compared with $\leq 50$ years), histodifferentiation (weak/moderate compared with poor differentiation), and surgical pathologic staging (staging I, II, III compared with IV). Our studies suggested that PGAM1 could be developed as an independent prognostic factor for HCC.

\section{Suppression of liver cancer cell Proliferation by PGAM1- shRNA}

In a pilot study, three shRNA expressing plasmids targeting PGAM1 were designed (termed as PGAM1-shRNAa, b, c), and their silencing effects were evaluated in HepG2 cells. Our data demonstrated that the expression of PGAM1 was remarkably reduced when HepG2 cells were treated with either PGAM1-shRNA-a or PGAM1shRNA-b whilst no apparent silencing effect could be observed if HepG2 cells were treated with PGAM1shRNA-c, compared with the negative control shNC (See additional file 1; Fig.S1).

To investigate the potential function of PGAM1, the liver cancer cell line HepG2 was treated with PGAM1shRNA. As shown in Fig. 4A, PGAM1 knockdown by PGAM1-shRNA-a resulted in remarkable inhibition of liver cancer cell proliferation, which was demonstrated by both MTT and clonogenic formation assays. MTT data showed that cell proliferation was suppressed by 
Table 2: Proteins identified by LC MS/MS.

\begin{tabular}{|c|c|c|c|c|c|c|c|c|}
\hline Protein name ${ }^{\mathrm{a}}$ & Gene name & Accession no.b & $\begin{array}{l}\text { Theotetical } \\
\text { molecular mass/PIc }\end{array}$ & Queries matched & $\begin{array}{l}\begin{array}{l}\text { Sequence } \\
\text { coverage (\%) }\end{array}\end{array}$ & MOWSE scored & Fold change $^{e}$ & Function \\
\hline \multicolumn{9}{|l|}{$\overline{\text { Up-regulation }}$} \\
\hline Macrophage migration inhibitory factor & MIF & P14174 & $12642 / 7.74$ & 1 & 9 & 57 & $3.1 \pm 0.9$ & Immune regulation \\
\hline Peptidyl-prolyl cis-trans isomerase A & PPIA & P62937 & $18233 / 7.68$ & 12 & 35 & 238 & $8.7 \pm 2.2$ & Protein folding \\
\hline Eukaryotic translation initiation factor $5 \mathrm{~A}-1$ & IF5A1 & P63241 & $17053 / 5.08$ & 3 & 22 & 214 & $2.1 \pm 0.9$ & Translation regulation \\
\hline Histone H2A.V & $\mathrm{H} 2 \mathrm{AV}$ & Q71UI9 & $13501 / 10.58$ & 2 & 28 & 138 & $3.9 \pm 1.1$ & Transcription regulation \\
\hline Phosphatidylethanolamine-binding protein 1 & PEBP1 & P30086 & $21160 / 7.01$ & 2 & 18 & 92 & $2.9 \pm 0.9$ & Signal transduction \\
\hline Peroxiredoxin-6 & PRDX6 & P30041 & $25135 / 6.00$ & 8 & 40 & 175 & $3.1 \pm 1.2$ & Metabolism \\
\hline Phosphoglycerate mutase 1 & PGAM1 & P18669 & $28902 / 6.67$ & 8 & 38 & 172 & $6.0 \pm 1.4$ & Metabolism \\
\hline 14-3-3 protein zeta/delta & $1433 Z$ & Q6P3U9 & $27902 / 4.73$ & 9 & 33 & 126 & $3.3 \pm 1.2$ & Signal transduction \\
\hline Triosephosphate isomerase & TPIS & P60174 & $26943 / 6.45$ & 21 & 45 & 406 & $2.9 \pm 0.8$ & Metabolism \\
\hline Proteasome activator complex subunit 1 & PSME1 & Q06323 & $28879 / 5.78$ & 1 & 7 & 59 & $6.7 \pm 2.1$ & Proteolysis \\
\hline Enoyl-CoA hydratase, mitochondrial & ECHM & P30084 & $31831 / 8.34$ & 1 & 7 & 51 & $2.6 \pm 0.8$ & Metabolism \\
\hline Annexin A4 & ANXA4 & P09525 & $36092 / 5.84$ & 1 & 5 & 98 & $2.4 \pm 0.5$ & Signal transduction \\
\hline Annexin A5 & ANXA5 & P08758 & $35972 / 4.94$ & 2 & 8 & 52 & $3.7 \pm 1.5$ & Signal transduction \\
\hline Aldo-keto reductase family 1 member $\mathrm{C} 3$ & AK1C3 & Q9UKL9 & $37227 / 8.05$ & 2 & 10 & 58 & $8.1 \pm 2.4$ & Metabolism \\
\hline Alpha-enolase & ENOA & Q6GMP2 & $47487 / 7.01$ & 20 & 27 & 485 & $7.8 \pm 1.9$ & Metabolism \\
\hline Keratin, type I cytoskeletal 19 & $\mathrm{~K} 1 \mathrm{C} 19$ & Q9P1Y4 & $44065 / 5.04$ & 17 & 32 & 344 & $5.8 \pm 1.9$ & Structural component \\
\hline Keratin, type I cytoskeletal 18 & $\mathrm{~K} 1 \mathrm{C} 18$ & P05783 & $48029 / 5.34$ & 17 & 12 & 285 & $5.1 \pm 1.7$ & Structural component \\
\hline Phosphoglycerate kinase 1 & PGK1 & P00558 & $44992 / 8.30$ & 6 & 13 & 73 & $18.3 \pm 4.3$ & Metabolism \\
\hline Isocitrate dehydrogenase [NADP] cytoplasmic & IDHC & 075874 & $46920 / 6.53$ & 1 & 3 & 53 & $2.6 \pm 0.3$ & Metabolism \\
\hline Keratin, type II cytoskeletal 8 & $\mathrm{~K} 2 \mathrm{C} 8$ & Q96J60 & $53671 / 5.52$ & 18 & 26 & 273 & $5.1 \pm 1.3$ & Structural component \\
\hline $60 \mathrm{kDa}$ heat shock protein, mitochondrial & $\mathrm{CH} 60$ & P10809 & $61190 / 5.70$ & 18 & 23 & 477 & $10 \pm 3.4$ & Molecular chaperone \\
\hline UDP-glucose 6-dehydrogenase & UGDH & 060701 & $5685 / 6.73$ & 2 & 8 & 75 & $3.1 \pm 1.1$ & Metabolism \\
\hline Glutamate dehydrogenase 1 & GLUD1 & P00367 & $61701 / 7.66$ & 4 & 26 & 187 & $8.3 \pm 2.6$ & Metabolism \\
\hline Aminoacylase-1 & $\mathrm{ACY} 1$ & Q03154 & $46084 / 5.77$ & 6 & 25 & 246 & $4.7 \pm 1.9$ & Proteolysis \\
\hline Glutathione transferase omega-1 & GSTO1 & P78417 & $27833 / 6.24$ & 7 & 18 & 264 & $8.3 \pm 2.4$ & Metabolism \\
\hline Ubiquitin & UBC & P62988 & $8560 / 6.56$ & 7 & 9 & 156 & $2.7 \pm 0.8$ & Proteolysis \\
\hline Cofilin-1 & COF1 & P23528 & $18723 / 8.22$ & 6 & 27 & 306 & $2.6 \pm 1.1$ & Signal transduction \\
\hline $\begin{array}{l}\text { Acidic leucine-rich nuclear phosphoprotein } 32 \text { family } \\
\text { member B }\end{array}$ & AN32B & Q92688 & $28944 / 3.94$ & 4 & 19 & 136 & $4.1 \pm 1.4$ & Protein binding \\
\hline Glyceraldehyde-3-phosphate dehydrogenase & G3P & P04406 & $36204 / 8.57$ & 63 & 59 & 1299 & $8.1 \pm 2.7$ & Metabolism \\
\hline Aldose reductase & ALDR & P15121 & $36237 / 6.51$ & 11 & 25 & 240 & $8.5 \pm 3.1$ & Protein binding \\
\hline
\end{tabular}


Table 2: Proteins identified by LC MS/MS. (Continued)

\begin{tabular}{|c|c|c|c|c|c|c|c|c|}
\hline Aldo-keto reductase family 1 member C2 & AK1C2 & P52895 & $37118 / 7.13$ & 5 & 20 & 229 & $14.8 \pm 4.5$ & Metabolism \\
\hline Aldo-keto reductase family 1 member B10 & AK1BA & O60218 & $36230 / 7.12$ & 3 & 13 & 131 & $13.1 \pm 3.8$ & Metabolism \\
\hline $\begin{array}{l}\text { Complement component } 1 \mathrm{Q} \text { subcomponent- } \\
\text { binding protein, mitochondrial }\end{array}$ & C1QBP & Q07021 & $31749 / 4.74$ & 2 & 10 & 78 & $13.3 \pm 3.7$ & Immune regulation \\
\hline 605 ribosomal protein $\mathrm{L} 6$ & RL6 & Q02878 & $32766 / 10.59$ & 11 & 26 & 202 & $11.3 \pm 3.7$ & Transcription regulation \\
\hline Poly $(\mathrm{rC})$-binding protein 2 & PCBP2 & Q15366 & $38962 / 6.33$ & 3 & 13 & 62 & $10.2 \pm 2.4$ & Protein binding \\
\hline Heat shock 70 kDa protein 1 & HSP71 & P08107 & $70299 / 5.48$ & 4 & 8 & 115 & $20.4 \pm 4.8$ & Molecular chaperone \\
\hline Trifunctional enzyme subunit alpha, mitochondrial & $\mathrm{ECHA}$ & P40939 & $83701 / 9.16$ & 4 & 8 & 98 & $3.8 \pm 1.9$ & Metabolism \\
\hline Annexin A6 & ANXA6 & P08133 & $76174 / 5.42$ & 4 & 3 & 92 & $11.4 \pm 3.2$ & Signal transduction \\
\hline Heat shock 70 kDa protein $1 \mathrm{~L}$ & HS71L & P34931 & $70737 / 5.76$ & 4 & 6 & 84 & $29.5 \pm 5.7$ & Molecular chaperone \\
\hline Protein disulfide-isomerase A4 & PDIA4 & P13667 & $73235 / 4.96$ & 3 & 4 & 81 & $11.4 \pm 3.6$ & Metabolism \\
\hline ATP synthase subunit beta, mitochondrial & ATPB & P06576 & $56525 / 5.26$ & 14 & 28 & 352 & $22.7 \pm 4.9$ & Metabolism \\
\hline Pyruvate kinase isozymes M1/M2 & KPYM & Q9BWB5 & $58480 / 7.96$ & 12 & 23 & 334 & $2.3 \pm 1.4$ & Metabolism \\
\hline Protein disulfide-isomerase & PDIA1 & P07237 & $57487 / 4.76$ & 3 & 5 & 84 & $8.8 \pm 3.6$ & Protein binding \\
\hline Delta-1-pyrroline-5-carboxylate synthetase & P5CS & P54886 & $88002 / 6.66$ & 6 & 6 & 178 & $14.3 \pm 4.1$ & Metabolism \\
\hline Desmoplakin & DESP & P15924 & $334063 / 6.44$ & 3 & 2 & 64 & $3.3 \pm 1.6$ & Structural component \\
\hline ATP-dependent DNA helicase 2 subunit 2 & KU86 & P13010 & $83232 / 5.55$ & 3 & 7 & 53 & $9.6 \pm 3.5$ & Protein binding \\
\hline Cullin-associated NEDD8-dissociated protein 1 & CAND1 & Q9P0H7 & $138029 / 5.52$ & 6 & 3 & 63 & $4.1 \pm 2.1$ & Transcription regulation \\
\hline ATP-dependent DNA helicase 2 subunit 1 & KU70 & P12956 & $70089 / 6.23$ & 9 & 5 & 107 & $3.1 \pm 1.6$ & Protein binding \\
\hline \multicolumn{9}{|l|}{ Down-regulation } \\
\hline Protein S100-A6 & S100A6 & P06703 & $10231 / 5.33$ & 2 & 28 & 53 & $3.8 \pm 1.4$ & Calcium ion binding \\
\hline Calpain small subunit 1 & CAPNS1 & P04632 & $28469 / 5.05$ & 4 & 13 & 157 & $3.1 \pm 1.6$ & Calcium ion binding \\
\hline Annexin A1 & ANXA1 & P04083 & $38922 / 6.57$ & 2 & 4 & 98 & $2.7 \pm 0.8$ & Calcium ion binding \\
\hline Interleukin-18 precursor (IL-18) & IL18 & Q14116 & $22597 / 4.54$ & 12 & 18 & 123 & $2.3 \pm 0.6$ & Immune regulation \\
\hline Transketolase & TKT & P29401 & $68531 / 7.58$ & 9 & 13 & 145 & $6.2 \pm 1.9$ & Metabolism \\
\hline Profilin-1 & PFN1 & P07737 & $15219 / 8.44$ & 6 & 21 & 140 & $3.4 \pm 1.7$ & Structural component \\
\hline $\begin{array}{l}\text { Pyruvate dehydrogenase E1 component alpha } \\
\text { subunit }\end{array}$ & PDHA1 & P08559 & $43296 / 8.35$ & 14 & 8 & 179 & $3.5 \pm 1.5$ & Metabolism \\
\hline Protein SET & SET & Q01105 & $33469 / 4.23$ & 2 & 16 & 96 & $4.4 \pm 1.7$ & Signal transduction \\
\hline Heat shock protein HSP 90-alpha & HS90A & P07900 & $85013 / 4.94$ & 40 & 26 & 428 & $2.8 \pm 0.5$ & Molecular chaperone \\
\hline Histone $\mathrm{H} 2 \mathrm{~A}$ type 2-A & $\mathrm{H} 2 \mathrm{~A} 2 \mathrm{~A}$ & Q6FI13 & $14087 / 10.90$ & 6 & 36 & 153 & $3.7 \pm 1.2$ & Transcription regulation \\
\hline Poly(rC)-binding protein 1 & PCBP1 & Q15365 & $37996 / 6.66$ & 9 & 17 & 118 & $2.6 \pm 1.4$ & Protein binding \\
\hline Lamin-A/C & LMNA & P02545 & $74385 / 6.57$ & 7 & 11 & 86 & $3.7 \pm 1.8$ & Protein binding \\
\hline
\end{tabular}

a For several proteins, a few isoforms were identified in the same individual.

${ }^{b}$ Accession numbers were derived from the ExPASy database.

' Theoretical molecular mass ( $\mathrm{kDa}$ ) and pl from the ExPASy database.

a Probability-based MOWSE (molecular weight search) scores.

e Expression change level in HepG2 cells compared with L02 cells. 


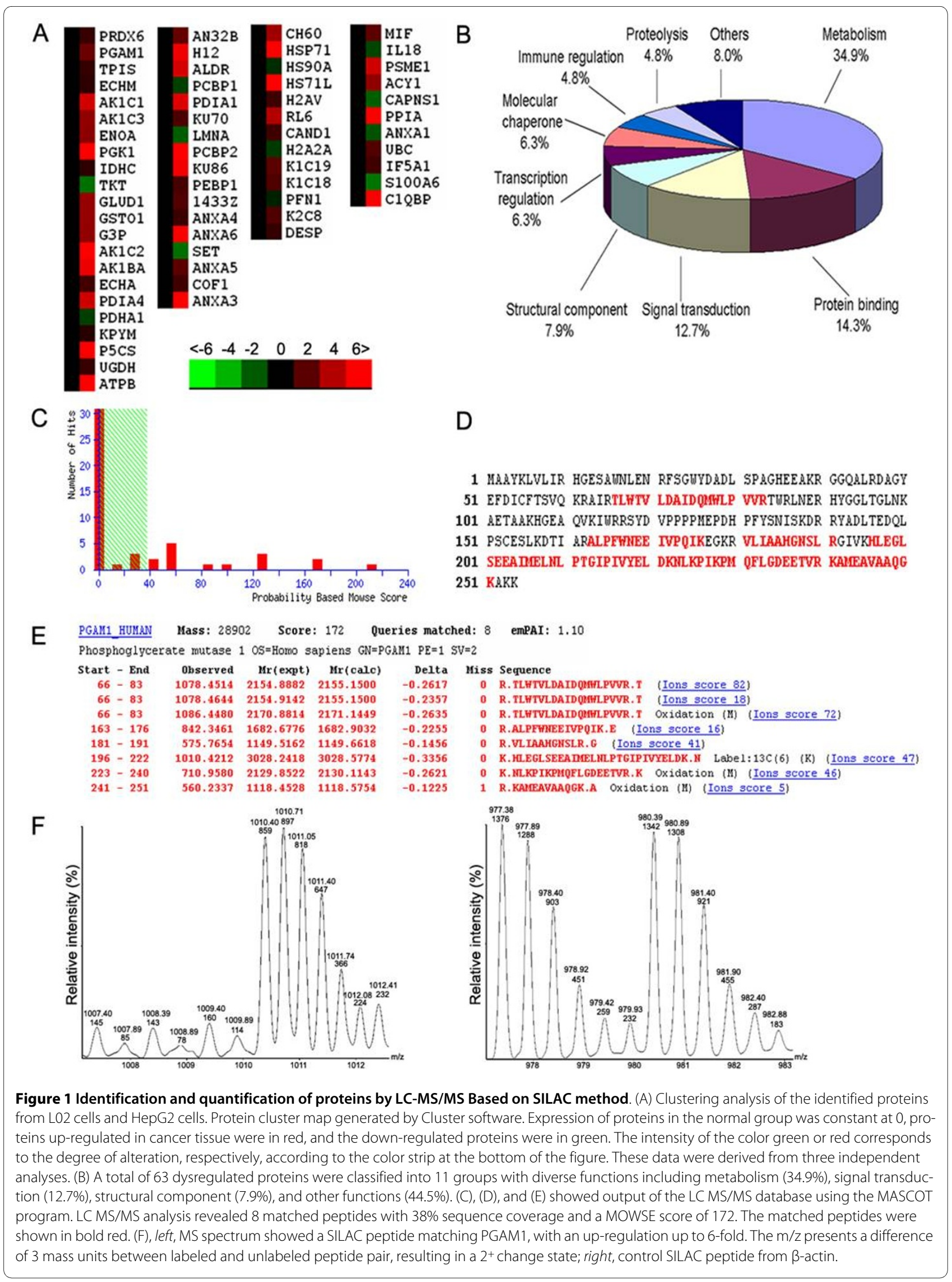




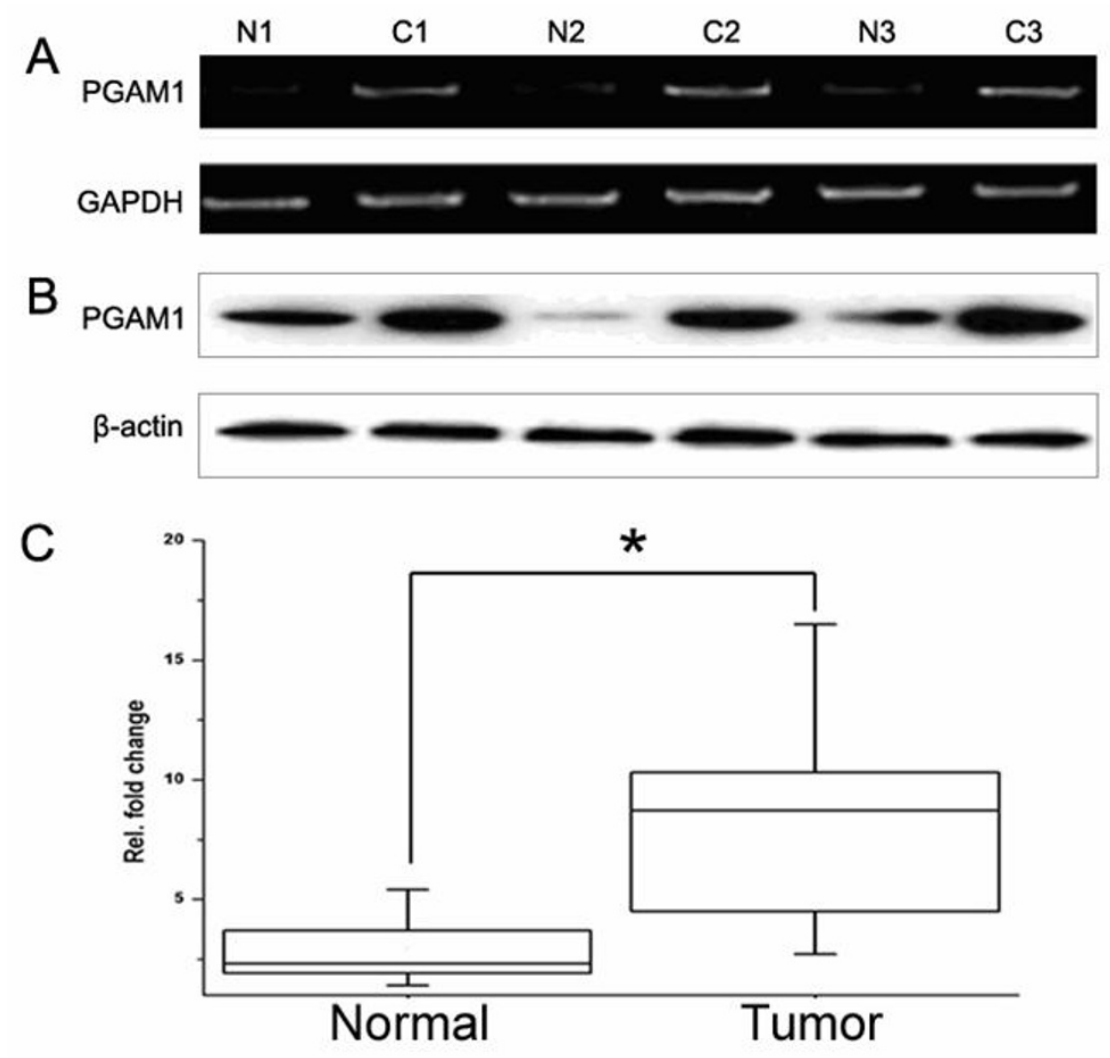

Figure 2 Overexpression of PGAM1 in HCCs. (A), expression level of PGAM1 mRNA was semi-quantified by RT-PCR. Pairs of the total mRNA were normalized by GAPDH. (B), representative results of Western blot analysis of HCCs and the adjacent noncancerous samples with $\beta$--actin as an internal control. (C), box chart, quantitative Western blot results of HCCs vs. the corresponding normal tissues. To ensure reproducibility, three independent experiments were performed. ${ }^{*}, p<0.01$, Student's $t$ test. $N$, normal liver tissue. $C$, cancer tissue.

PGAM1-shRNA-a in duration-dependent manner, and the proliferation ratio was decreased by $48.6 \%$ at $72 \mathrm{~h}$ posttransfection, compared to the negative control (shNC). In colony formation assay, upon 14-day continuous culture, the clone numbers were $92 \pm 3.84,69 \pm 3.38$, and $65 \pm 4.33$ in untreated control, mock control (Lipofectamine 2000), and negative control (shNC), respectively (Fig. 4A). Meanwhile the clone number in the
PGAM1-siRNA-a group was $25 \pm 3.02$ with an inhibition ratio of 72.8\% (Dunnett's $t$ test, $p<0.01$ ) (Fig. 4B).

\section{Knockdown of PGAM1 expression induced cancer cell apoptosis}

To examine if loss of PGAM1 expression induces apoptotic cell death, flow cytometric analysis was performed to measure the sub- $G_{1}$ value of HepG2 liver cancer cell

Table 3: PGAM1 immunoreactivity in normal liver tissues and hepatocellular carcinoma tissues.

\begin{tabular}{|c|c|c|c|c|c|c|c|}
\hline $\begin{array}{l}\text { Histodifferentiation } \\
\text { Grading }\end{array}$ & Cases & -- & + & ++ & $+++^{a}$ & Total Score & Average Score $^{a}$ \\
\hline Normal liver tissues & 21 & $19 \%(4 / 21)$ & $81 \%(17 / 21)$ & 0 & 0 & 48 & $2.29 \pm 1.02$ \\
\hline Hepatocellular carcinoma & 54 & 0 & $33 \%(18 / 54)$ & $26 \%(14 / 54)$ & $41 \%(22 / 54)$ & 428 & $7.93 \pm 2.58$ \\
\hline
\end{tabular}

a Student's t test, $p<0.01$. 
Table 4: Relevance of HCC characteristics to PGAM1 immunoreactivity: histodifferentiation to PGAM1.

\begin{tabular}{lccccccc}
\hline Histodifferentiation Grading & Cases & -- & + & ++ & $+++^{\mathbf{a}}$ & Total Score & Average Score $^{\mathbf{b}}$ \\
\hline Well differentiated & 11 & 0 & $73 \%(8 / 11)$ & $18 \%(2 / 11)$ & $9 \%(1 / 11)$ & 63 & $5.73 \pm 2.46$ \\
Moderately differentiated & 28 & 0 & $36 \%(10 / 28)$ & $39 \%(11 / 28)$ & $25 \%(7 / 28)$ & 217 & $7.75 \pm 2.68$ \\
Poorly differentiated & 15 & 0 & 0 & $7 \%(1 / 15)$ & $93 \%(14 / 15)$ & 148 & $9.87 \pm 3.17$ \\
\hline
\end{tabular}

a Cross $x^{2}$ test, $p<0.01$.

bOne-way ANOVA analysis, $p<0.05$; LSD-t test, $p<0.05$ (well versus moderately; well versus poorly; moderately versus poorly).

treated with PGAM1-shRNA-a. As shown in Fig 4C, a clear-cut difference was observed at $72 \mathrm{~h}$ posttransfection, and the apoptosis/PI positive percentage reached 48.6\% for PGAM1-shRNA-a treated cells compared with $1.0 \%, 1.2 \%$ and $7.8 \%$ for untreated, Lipofectamine 2000 and HK-shRNA, respectively $(p<0.01)$. As the sub- $\mathrm{G}_{1}$ values measured by flow cytometry represent dead cells arising from both apoptosis and necrosis, a more specific TUNEL assay was applied to measure the apoptotic cells induced by PGAM1-shRNA-a. Cell nuclei with DNA strand breaks were revealed by labeling free 3'-OH termini and observed to stain dark green as viewed by fluorescence microscopy, indicating apoptosis, and were recorded as TUNEL-positive nuclei. As shown in Fig. 4D, a significant increase of TUNEL-positive nuclei was observed in the PGAM1-shRNA-a transfected cells (73.7 $\pm 2.01 \%$ ), compared with the control groups, $2.4 \pm 0.67 \%$ (Untreated control), $10.2 \pm 1.34 \%$ (Lipofectamine 2000), and $15.8 \pm 1.67 \%$ (NC-shRNA control) (Dunnett's $t$ test, $p$ $<0.01$ ). Collectively, data obtained from diverse experiments demonstrated that suppression of PGAM1 expression resulted in massive liver cancer cell apoptosis.

To rule out the potential off-target effect, HepG2 cells were treated with another PGAM1 specific shRNA (PGAM1-shRNA-b). As shown in Fig. S2 (A-C) in additional file 1, treatment with PGAM1-shRNA-b in HepG2 cells resulted in remarkable inhibition of cell proliferation, and induction of apoptosis, which were evidenced by the observations from MTT assay, clonogenic formation assay and TUNEL assay.

PGAM1-shRNA-a inhibited xenograft tumor growth in vivo To extend the above findings, in vivo studies were performed using HepG2 xenograft tumor bearing mice. Tumor volumes were measured every 2 days during treatment duration until animals were sacrificed, and no animal death or signs of possible toxicity were observed during this period (data not shown) [34]. Although the tumors of all mice were approximately equal in initial volumes, significant differences in tumor growth were observed upon treatment with PGAM1-shRNA-a. As shown in Fig 5A, the average tumor volumes at the termination of the experiment were $515.65 \pm 40.14,455.58 \pm$
40.23, and $410.23 \pm 34.16 \mathrm{~mm}^{3}$ for PBS, Lipofectamine 2000 , and NC-shRNA, respectively $(p>0.05)$. In comparison, tumor volumes in mice treated with PGAM1shRNA-a were $212.71 \pm 24.28 \mathrm{~mm}^{3}$, which were on average over $58.7 \%$ smaller than those in controls treated with PBS (Student's $t$ test, $p<0.01$ ) (Fig. 5A). To validate PGAM1-shRNA-a mediated suppression of PGAM1 expression, immunohistochemical analysis against antiPGAM1 antibody was performed to detect PGAM1 expression level in the tumor-bearing mice which had been subjected to PGAM-shRNA treatment. As shown in Fig. 5B, tail intravenous injections of PGAM-shRNA-a resulted in more than $75 \%$ suppression of PGAM1 in tumor-bearing mice, whilst no obvious difference could be observed regarding the expression level of PGAM1 in the control mice either treated with Lipofectamine 2000 or NC-shRNA, relative to injection with PBS.

As PGAM1 repression inhibited cancer cell growth and induced remarkable apoptotic cell death in vitro, we have particular interest to examine the potential function underlying PGAM1-shRNA-a mediated anti-tumor activity in vivo. To this end, tumor cell proliferation and apoptosis were assessed by Ki-67 immunoreactivity analysis and TUNEL assay. As shown in Fig. 5B, Ki-67 positive nuclei were decreased over $68 \%$ for control with PBS (Student's $t$ test, $p<0.01$ ). In contrast, TUNEL assay showed a remarkably higher percentage of TUNEL positive nuclei in PGAM1-shRNA-a treated group, relative to injection of PBS control. Our data suggested that suppression of PGAM1 expression mediated by PGAM1shRNA-a could significantly inhibit cell proliferation and induce apoptosis in vivo.

\section{Discussion}

Hepatocellular carcinoma (HCC), one of the most common malignancies worldwide, remains a major health problem with increasing incidence rates even to date $[4,35]$, and there is an urgent need to identify novel molecular targets for diagnosis, prognosis and treatment of HCC. In the current study, a SILAC-based quantitative proteomics approach was applied to profile the altered expressed proteins between HepG2 cells and L02 cells, resulting in identification of 63 distinct proteins with 


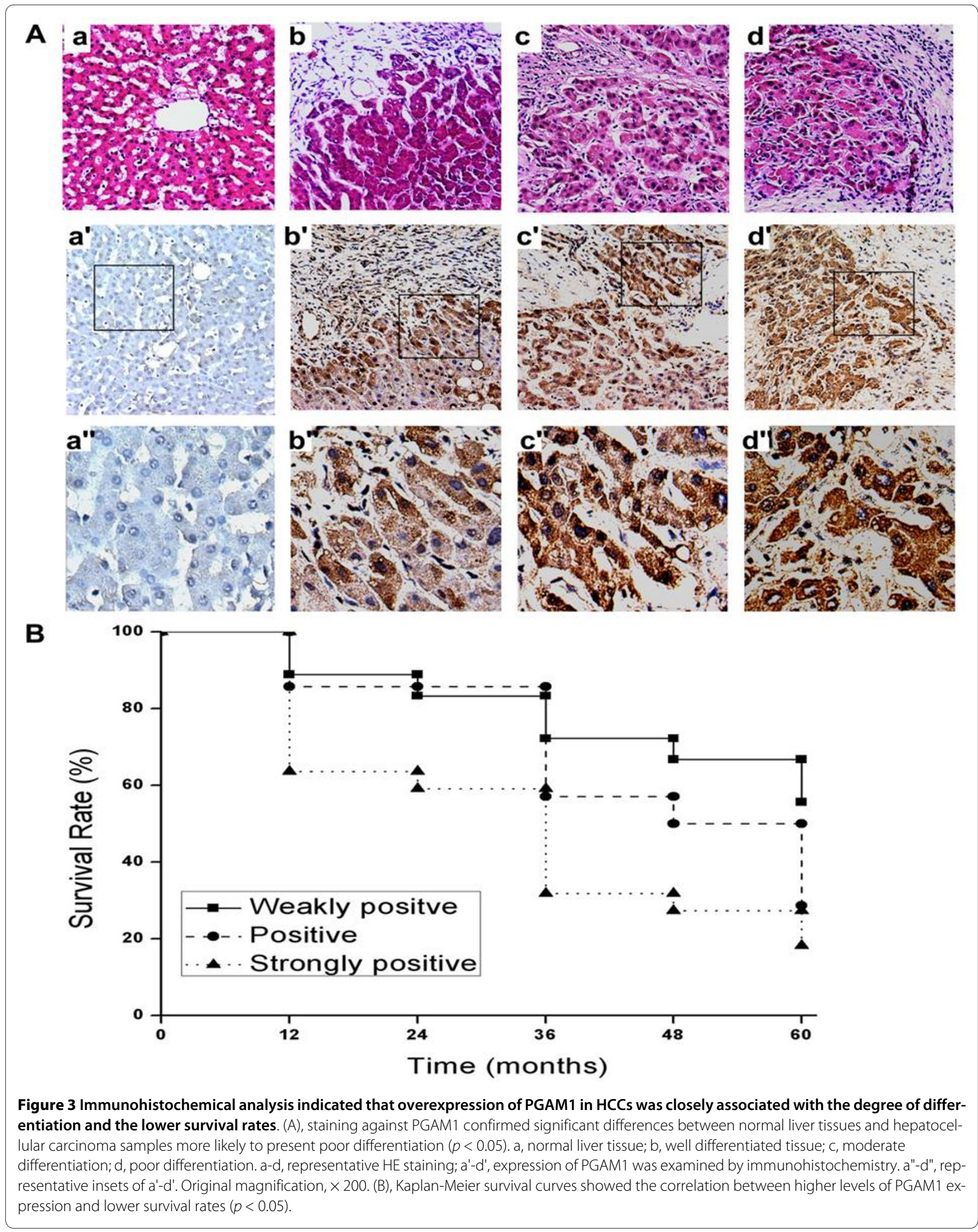




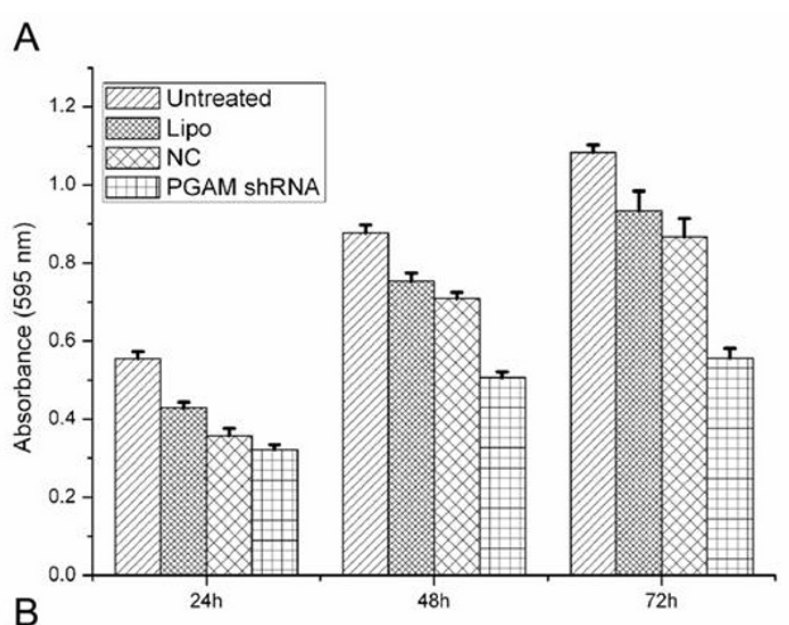

a

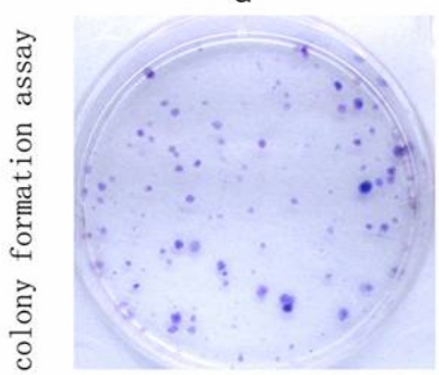

C
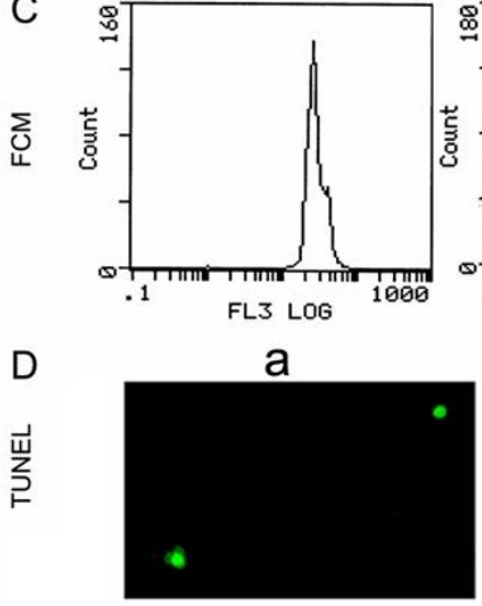

C

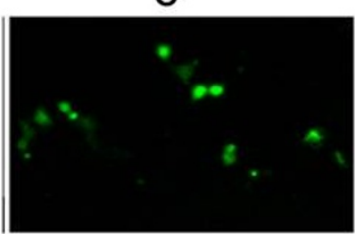

b
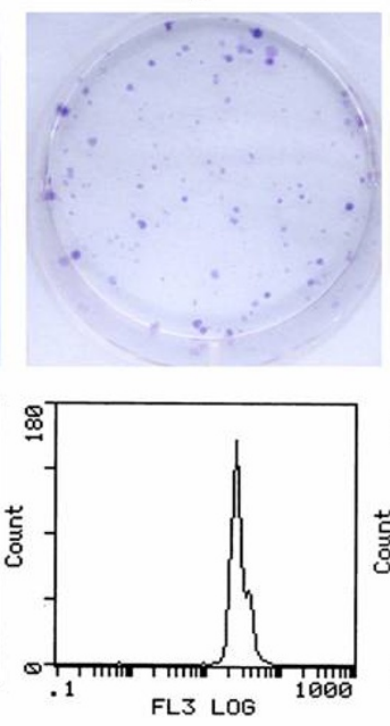

b

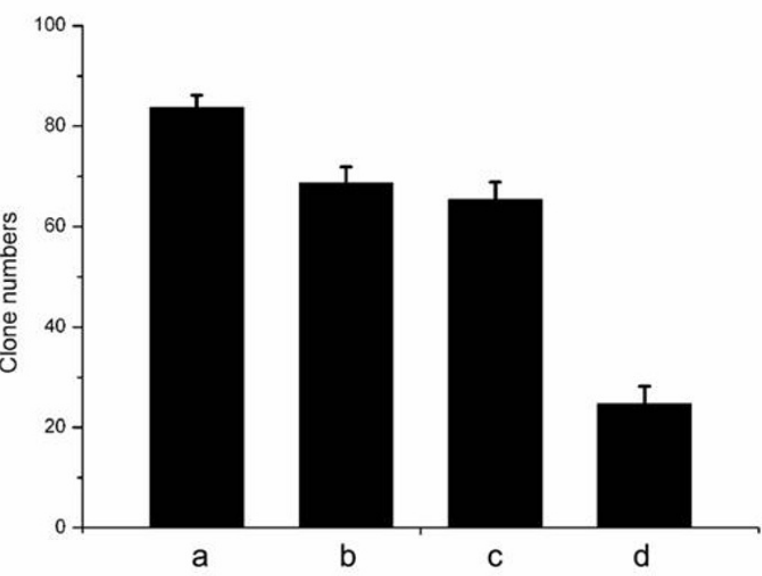

C

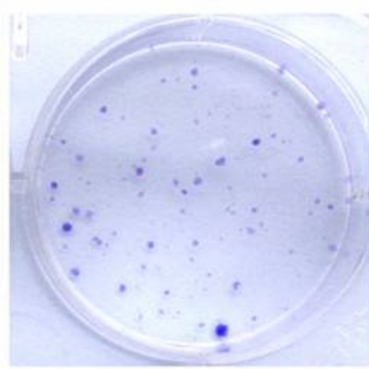

d
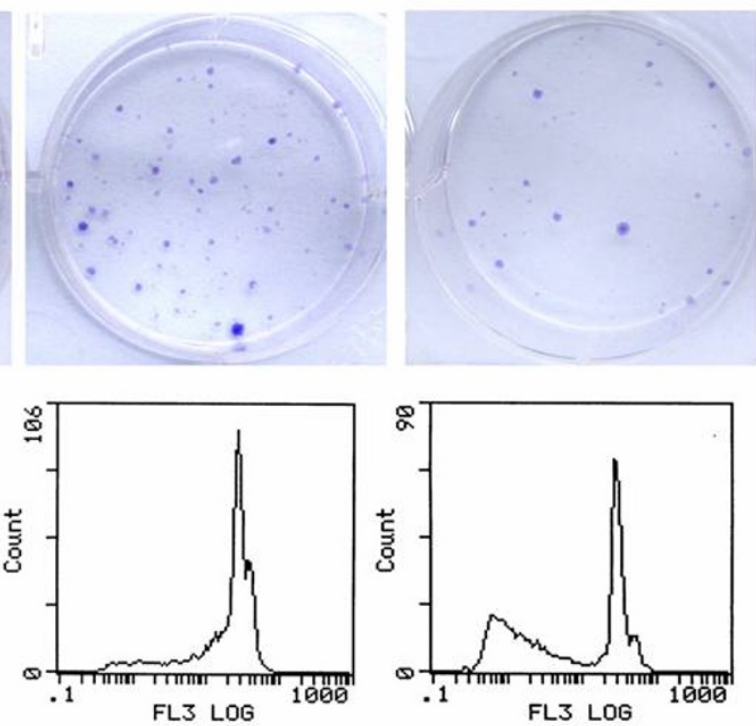

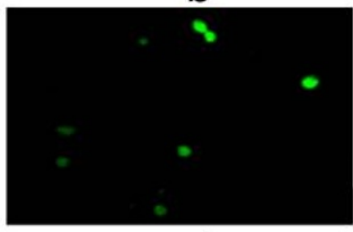

d

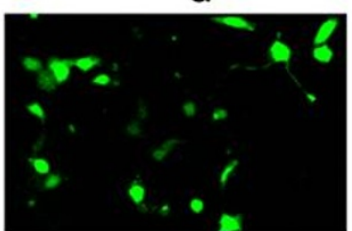

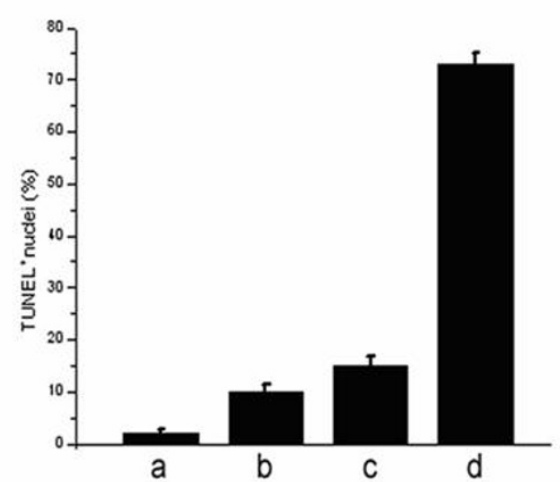

Figure 4 Suppression of PGAM1 by PGAM1-shRNA-a resulted in cell growth arrest and induced apparent apoptosis in vitro. (A) Evaluation of the antiproliferation effects using MTT assay. Inhibition of cell growth by siRNA against PGAM1 was in a duration-dependent manner and the proliferation rate was decreased to $48.6 \%$ at $72 \mathrm{~h}$ posttransfection. (B) Survival rates of hepatoma cells were examined by colony formation assay. $24 \mathrm{~h}$ after transfection, cells were allowed to grow at a density of 300 cells/dish for additional two weeks before staining with Crystal Violet. (C) Flow cytometry analysis was performed and the subdiploid peak increased after $72 \mathrm{~h}$ of transfection $(p<0.05)$. (D) Cell apoptosis was assessed by TUNEL assay which showed a remarkably greater percentage of TUMEL positive nuclei of the PGAM1-shRNA-a group vs. the control group. a, untreated; b, Lipofectamine 2000; c, shNC; d, PGAM1-shRNA-a. Results represent the average of three independent experiments and data were shown as mean \pm S.D. 


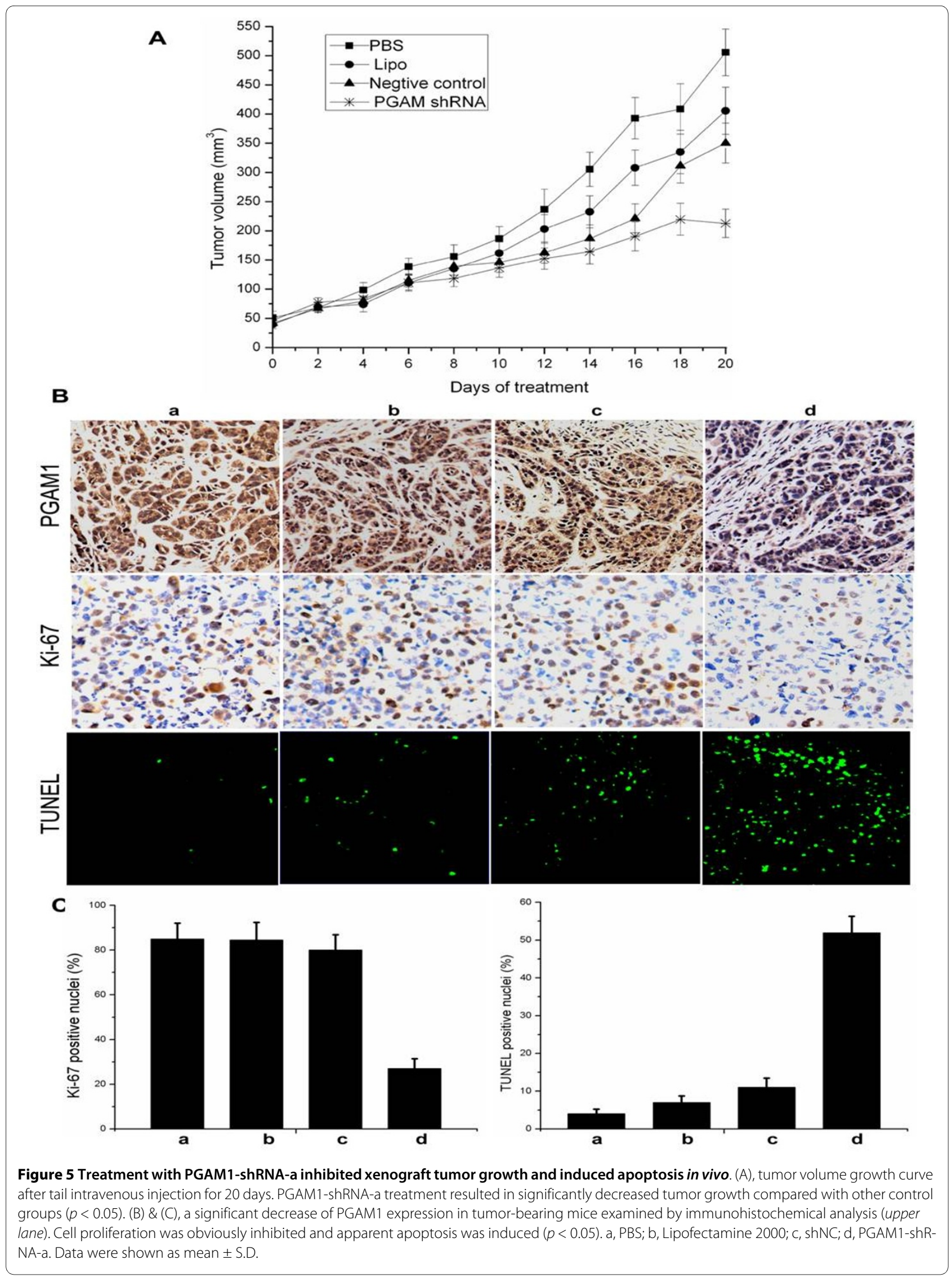


altered expression, which were associated with cell metabolism, proliferation and/or apoptosis. Among them, Profilin1, a member of profilin family, also known as PFN1, was ubiquitous and down-regulated more than 3-fold in HepG2 cells. As a tumor suppressor in breast cancer cells, PFN1 was reported to be involved in multiple cell behaviors, including cell adhesion, growth, proliferation and signal transduction [36,37]. On the contrary, some key enzymes participated in glycolytic pathway were overexpressed in HepG2 cells, exemplified by enolase, which catalysed the conversion of 2-phosphoglycerate to phosphoenolpyruvate; Phosphoglycerate kinase 1 was overexpressed more than 18-fold which catalysed the conversion of 1,3-bisphosphoglycerate to 3-phosphoglycerate coupled with the generation of ATP. Most intriguingly, we found that phosphoglycerate mutase 1 (PGAM1) was shown an upregulation up to 6-fold. As an enzyme in glycolysis, PGAM1 was ubiquitously expressed in human, Bacillus stearothermophilus [38], Escherichia coli [39], Entamoeba histolytica [40], et al, functions to catalyze the interconversion of 3-phosphoglycerate and 2-phosphoglycerate with 2,3-bisphosphoglycerate (2,3BPG) $[15,41]$. A recent study revealed that PGAM1 was overexpressed in breast cancer, and suppression PGAM1 expression displayed a profound antiproliferative effect, underscoring its important role in carcinogenesis [14]. Obviously, more extensive investigations on the functions of PGAM1 which was upregulated in $\mathrm{HCC}$ are required to elucidate the role of PGAM1 in hepatocarcinogenesis.

As an intracellular hallmark of neoplasm, the increased level of glycolysis enables cancer cells to survive despite the poor conditions [42]. Fifty years ago, Otto Warburg had demonstrated that cancer cells were oxygen-independent for producing ATP, particularly in the hypoxic tumor microenvironment $[9,43]$. Previous studies demonstrated that hypoxia inducible factor (HIF) enhanced glycolysis by increasing the transcription of glycolytic enzyme genes to protect cancer cells from energy starvation $[44,45]$. It has been clear that, highly proliferative cancer cells need to synthesize fatty acids de novo to continually provide lipids for membrane production. An increased glycolytic flux could lead to an augmented amount of metabolic precursors for the synthesis of nucleic acid, amino acid or lipid which are essential for the cancer cell growth and proliferation [46,47]. Conversely, inhibition of glycolytic pathway results in decreasing not only amino acid and lipid synthesis but also ATP production. An increased AMP/ATP ratio is important for activation of AMP-activated protein kinase (AMPK). Once activated by energy starvation, AMPK directly phosphorylates tuberous sclerosis complex 2 (TSC2) on T1227 and S1345, stimulates its GTPase activity resulting in the inhibition of Ras homologue enriched in brain (Rheb) which is essential for mammalian target of rapamycin (mTOR) activity. Moreover, inactivation of mTOR was strongly correlated with cell growth arrest and apoptosis [12]. On the other hand, acetyl-CoA carboxylase $(\mathrm{ACC})$ is an important rate-controlling enzyme for the synthesis of malonyl-CoA, which is not only a critical precursor for biosynthesis of fatty acids but also a potent inhibitor of mitochondrial fatty acid oxidation. In this case, phosphorylation and inhibition of ACC by AMPK leads to a fall in malonyl-CoA content and a subsequent decrease in triglyceride synthesis concomitantly with an increase in $\beta$-oxidation [48]. In general, it has been considered that glycolysis plays a pivotal role for ATP production and cell growth in transformed cells (Fig. 6). Considerable effort has been made to elucidate the close correlation between rates of aerobic glycolysis and the degree of malignancy [49]. In view of this, the decreased of glucose level should be strongly tumoricidal for transformed cells proliferation [50]. For example, 3bromo pyruvate, an inhibitor of hexokinase, has been demonstrated to inhibit glycolysis and effectively kill hepatoma cells in tissue culture even at a lower concentration [51]. Furthermore, in the presence of GAPDH, Nm23-H1 could phosphorylate PGAM1 and inhibit PGAM1 activity resulting in suppression of glycolysis and inducing growth arrest in various cancer cells, including glioblastoma cell line Tx3095, small lung cancer cell line GLC4, beast carcinoma cell lines MCF-7 and MDA-MB453, etc [13]. Under this circumstance, PGAM1 should be a potential diagnostic biomarker, as well as a therapeutic target for various malignancies.

Clinico-pathological analysis indicated that overexpression of PGAM1 was associated with $66.7 \% \mathrm{HCC}$, and strongly correlated with poor differentiation and decreased survival rates $(p<0.01)$. Our studies suggested that PGAM1 has the potential to be developed as a useful diagnostic and prognostic marker for HCC. Further studies should be performed to evaluate if PGAM1 could be utilized as an independent biomarker for early diagnosis of HCC. On the other hand, silencing expression of PGAM1 significantly induced liver cancer cell apoptosis both in vitro and in vivo. Apoptosis is a major barrier that must be circumvented during malignant transformation. Cancer cells evolve to evade apoptosis so that they can escape from being cleared away by the surveillance system and can survive in the crucial tumor microenvironment, such as hypoxia and nutrition depletion [52]. Defective apoptosis was considered as a major causative factor in the genesis and development of many human cancers, triggering tumor selective apoptosis in cancer cells exploited into a promising strategy for clinical treatment [53]. The strong apoptosis-promoting activities mediated by PGAM1-siRNA suggested that PGAM1 would be an attractive drug target for therapeutic treatment with HCC. Further intensive studies should be con- 


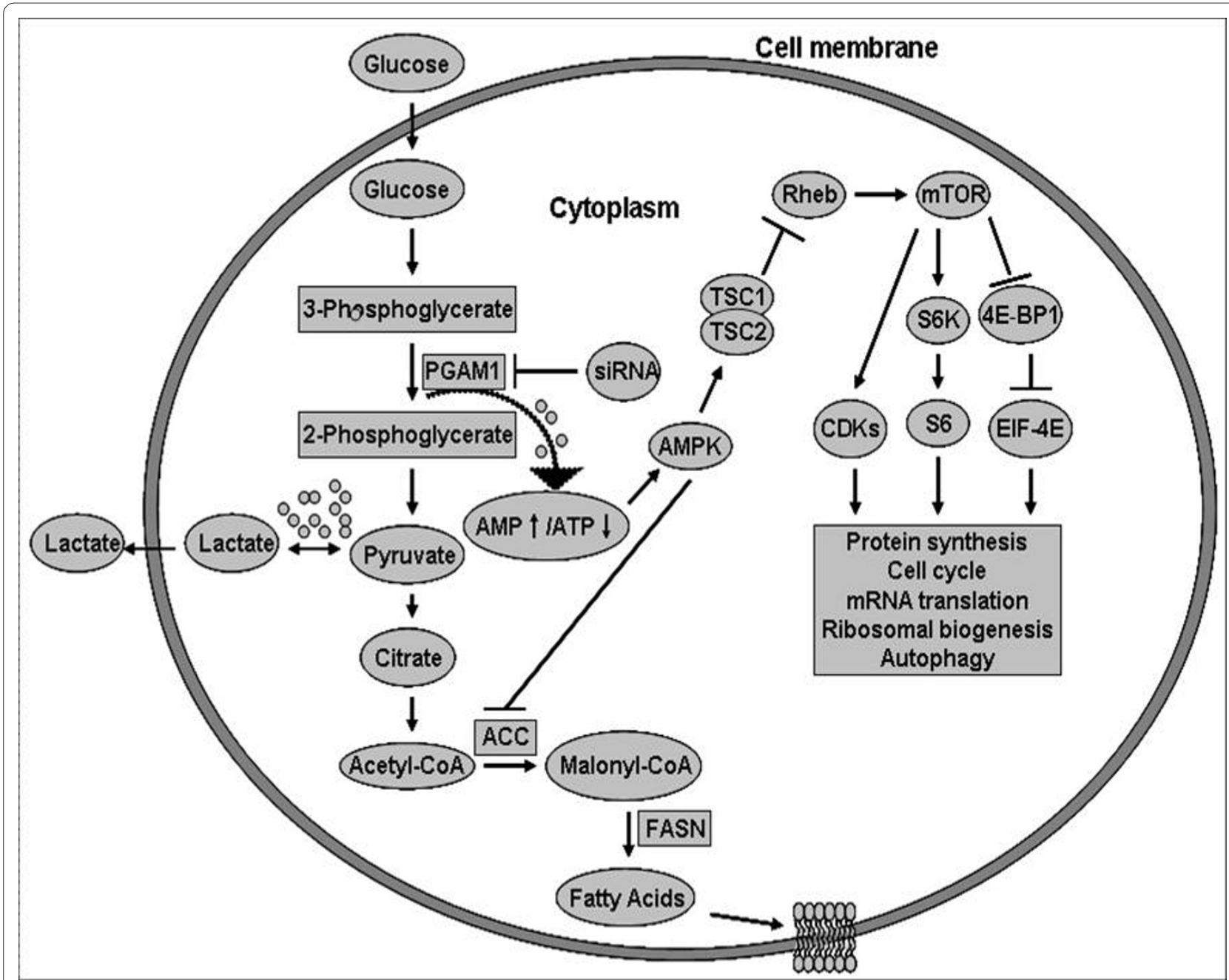

Figure 6 A model of glycolysis illustrating the possible involvement in cellular energy signaling pathways. Arrows represent activation, whereas bars represent inhibition. Dotted arrows indicate the increased ratio of AMP/ATP. Small circles represent ATP. AMPK, AMP-activated protein kinase; TSC, tuberous sclerosis complex; Rheb, Ras homologue enriched in brain; mTOR, mammalian target of rapamycin; S6K, ribosomal protein S6 kinases; 4E-BP1, elF4E-binding protein; ACC, acetyl-CoA carboxylase; FASN, fatty-acid synthase; CDKs, cyclin dependent kinases.

ducted to pinpoint the molecular mechanisms underlying PGAM1-siRNA mediated cell death.

\section{Conclusions}

So far, a small but increasing number of reports were documented regarding targeting a cellular metabolic enzyme for cancer therapy [54], thus the current study provided new insights for potential clinical treatment of HCC using siRNA-mediated suppression of PGAM1 expression since RNAi technology has emerged as a powerful tool to silence gene expression in mammalian cells so that it could be used to investigate the gene function [55]. Hopefully, shRNA-mediated suppression of PGAM1 expression, combined with conventional surgical resection and chemotherapy strategies, will open a new avenue for clinical treatment of hepatocellular carcinoma.

\section{Additional material}

Additional file 1 A brief description of PGAM1-shRNA strategy. There are one table (Table S1) and two figures (Fig.S1 and Fig.S2) in the additional file 1. The sequences of PGAM1-shRNA- $a,-b$ and $-c$ were listed in Table S1. Fig. S1 showed the effect of PGAM1-shRNA-a, -b, -c on suppression of PGAM1 expression in HepG2 cells. Fig. S2 elaborated on the PGAM1-shRNA$\mathrm{b}$ induced inhibition of HepG2 cell proliferation and induction of apoptosis in vitro to rule out the potential off-target effect.

\section{Competing interests}

The authors declare that they have no competing interests.

\section{Authors' contributions}

$\mathrm{CHH}$ and YQW conceived of the study; FLR, RL, YLL and YZ and LJC carried out the proteomics studies; HW and HYZ and FLR collected samples and participated in prognosis analysis; XCC, DQZ, HW and FLR were involved in the pathology analysis; APT assisted in molecular experiments; FLR and RL performed the statistical analysis, and FLR, RL, and CHH drafted the manuscript; All authors have read and approved the final manuscript. 


\section{Acknowledgements}

This work was supported by the National 863 High Tech Foundation (2007AA021205, 2008ZX10002-009), and Chinese NSFC (30771125).

\section{Author Details}

1The State Key Laboratory of Biotherapy, West China Hospital, Sichuan University, Chengdu, 610041, China, 2Department of Hepatobiliary Pancreatic Surgery, West China Hospital, Sichuan University, Chengdu, 610041, China and 3The School of Medicine, Yangtze University, Shashi, Hubei, 434000, China

Received: 9 November 2009 Accepted: 19 April 2010

Published: 19 April 2010

\section{References}

1. Chen Y, Lin MC, Yao H, Wang H, Zhang A, Yu J, Hui CK, Lau GK, He M, Sung J, Kung H: Lentivirus-Mediated RNA interference targeting enhancer of Zeste Homolog 2 inhibits hepatocellular carcinoma growth through down-regulation of Stathmin. Hepatology 2007, 46:200-208,

2. Avila MA, Berasain C, Sangro B, Prieto J: New therapies for hepatocellular carcinoma. Oncogene 2006, 25:3866-3884.

3. El-Serag HB, Rudolph KL: Hepatocellular carcinoma: epidemiology and molecular carcinogenesis. Gastroenterolog y 2007, 132:2557-2576.

4. Bosch FX, Ribes J, Diaz M, Cleries R: Primary liver cancer: worldwide incidence and trends. Gastroenterology 2004, 127:S5-S16.

5. Yau T, Chan P, Epstein R, Poon RT: Management of advanced hepatocellular carcinoma in the era of targeted therapy. Liver Int 2009, 29:10-17.

6. Budhu A, Jia HL, Forgues M, Liu CG, Goldstein D, Lam A, Zanetti KA, Ye QH, Qin LX, Croce CM, Tang ZY, Wang XW: Identification of metastasisrelated microRNAs in hepatocellular carcinoma. Hepatology 2008, 47:897-907.

7. Hwang LH: Gene therapy strategies for hepatocellular carcinoma. J Biomed Sci 2006, 13:453-468.

8. Dang CV, Semenza GL: Oncogenic alterations of metabolism. Trends Biochem Sci 1999, 24:68-72.

9. Warburg O: On the origin of cancer cells. Science 1956, 123:309-314.

10. Kondoh H, Lleonart ME, Gil J, Wang J, Degan P, Peters G, Martinez D, Carnero A, Beach D: Glycolytic enzymes can modulate cellular life span. Cancer Res 2005, 65:177-185.

11. Pelicano H, Martin DS, Xu RH, Huang P: Glycolysis inhibition for anticancer treatment. Oncogene 2006, 25:4633-4646.

12. Inoki K, Zhu T, Guan KL: TSC2 mediates cellular energy response to control cell growth and survival. Cell 2003, 115:577-590

13. Engel M, Mazurek S, Eigenbrodt E, Welter C: Phosphoglycerate mutasederived polypeptide inhibits glycolytic flux and induces cell growth arrest in tumor cell lines. J Biol Chem 2004, 279:35803-35812.

14. Evans MJ, Saghatelian A, Sorensen EJ, Cravatt BF: Target discovery in small-molecule cell-based screens by in situ proteome reactivity profiling. Nat Biotechnol 2005, 23:1303-1307.

15. de Atauria P, Repiso A, Oliva B, Vives-Corrons IL, Climent F, Carreras J: Characterization of the first described mutation of human red blood cell phosphoglycerate mutase. Biochim Biophys Acta 2005, 1740:403-410.

16. Zhang J, Yu L, Fu Q, Gao J, Xie Y, Chen J, Zhang P, Liu Q, Zhao S: Mouse phosphoglycerate mutase $M$ and $B$ isozymes: $C D N A$ cloning, enzyme activity assay and mapping. Gene 2001, 264:273-279.

17. Sakoda S, Shanske S, DiMauro S, Schon EA: Isolation of a cDNA encoding the $B$ isozyme of human phosphoglycerate mutase (PGAM) and characterization of the PGAM gene family. J Biol Chem 1988, 263:16899-16905.

18. Betrán E, Wang W, Jin L, Long M: Evolution of the phosphoglycerate mutase processed gene in human and chimpanzee revealing the origin of a new primate gene. Mol Biol Evol 2002, 19:654-663.

19. Narayanan NK, Narayanan BA, Nixon DW: Resveratrol-induced cell growth inhibition and apoptosis is associated with modulation of phosphoglycerate mutase B in human prostate cancer cells: twodimensional sodium dodecyl sulfate-polyacrylamide gel electrophoresis and mass spectrometry evaluation. Cancer Detect Prev 2004, 28:443-452.

20. Durany N, Joseph J, Jimenez OM, Climent F, Fernández PL, Rivera F, Carreras J: Phosphoglycerate mutase, 2, 3-bisphosphoglycerate phosphatase, creatine kinase and enolase activity and isoenzymes in breast carcinoma. Br J Cancer 2000, 82:20-27.

21. Usuba T, Ishibashi Y, Okawa Y, Hirakawa T, Takada K, Ohkawa K: Purification and identification of monoubiquitin-phosphoglycerate mutase B complex from human colorectal cancer tissues. Int I Cancer 2001, 94:662-668.

22. Liu L, Wang S, Zhang Q, Ding Y: Identification of potential genes/ proteins regulated by Tiam 1 in colorectal cancer by microarray analysis and proteome analysis. Cell Biol Int 2008, 32:1215-1222.

23. Chen G, Gharib TG, Wang H, Huang CC, Kuick R, Thomas DG, Shedden KA, Misek DE, Taylor JM, Giordano TJ, Kardia SL, lannettoni MD, Yee J, Hogg PJ, Orringer MB, Hanash SM, Beer DG: Protein profiles associated with survival in lung adenocarcinoma. Proc Natl Acad Sci USA 2003, 23:13537-13542.

24. Li C, Xiao Z, Chen Z, Zhang X, Li J, Wu X, Li X, Yi H, Li M, Zhu G, Liang S: Proteome analysis of human lung squamous carcinoma. Proteomics 2006, 6:547-558

25. Turhani D, Krapfenbauer K, Thurnher D, Langen H, Fountoulakis M: Identification of differentially expressed, tumor-associated proteins in oral squamous cell carcinoma by proteomic analysis. Electrophoresi 2006, 27:1417-1423.

26. Fang MZ, Liu C, Song Y, Yang GY, Nie Y, Liao J, Zhao X, Shimada Y, Wang L, Yang CS: Over-expression of gastrin-releasing peptide in human esophageal squamous cell Carcinomas. Carcinogenesis 2004, 25:865-871.

27. Tong A, Wu L, Lin Q, Lau QC, Zhao X, Li J, Chen P, Chen L, Tang H, Huang C, Wei Y: Proteomic analysis of cellular protein alterations using a hepatitis B virus-producing cellular model. Proteomics 2008 , 8:2012-2023.

28. Kuramitsu Y, Nakamura K: Current progress in proteomic study of hepatitis C virus-related human hepatocellular carcinoma. Expert Rev Proteomics 2005, 2:589-601.

29. Ariizumi S, Katagiri S, Katsuragawa H, Kotera Y, Yamamoto M: Sectionectomy is suitable for patients with $\mathrm{T} 2$ hepatocellular carcinoma according to the modified international union against cancer TNM classification. Dig Surg 2007, 24:342-348.

30. Jin $X$, Yang YD, Chen $K, L$ L ZY, Zheng L, Liu YP, Chen SH, Yu CH, Jiang XY, Zhang CY, Li YM: HDMCP uncouples yeast mitochondrial respiration and alleviates steatosis in L02 and hepG2 cells by decreasing ATP and H2O2 levels: a novel mechanism for NAFLD. J Hepatol 2009, 50:857-860.

31. Wei Y, Zhao X, Kariya Y, Teshigawara K, Uchida A: Inhibition of proliferation and induction of apoptosis by abrogation of heat-shock protein (HSP) 70 expression in tumor cells. Cancer /mmunol Immunother 1995, 40:73-78.

32. Li Z, Huang C, Bai S, Pan X, Zhou R, Wei Y, Zhao X: Prognostic evaluation of epidermal fatty acid-binding protein and calcyphosine, two proteins implicated in endometrial cancer using a proteomic approach. Int $J$ Cancer 2008, 123:2377-2383

33. Zhou L, Jiang Y, Tan A, Greenlee AR, Shen Y, Liu L, Yang Q: Silencing of NRas gene expression using shRNA decreases transformation efficiency and tumor growth in transformed cells induced by anti-BPDE. Toxicol Sci 2008, 105:286-94.

34. Bai Y, Deng $H$, Yang Y, Zhao X, Wei Y, Xie G, Li Z, Chen X, Chen L, Wang Y, Su D, Qian Z, Zhong Q, Luo H, Yi T: VEGF-targeted short hairpin RNA inhibits intraperitoneal ovarian cancer growth in nude mice. Oncology 2009, 77:385-394

35. El-Serag HB, Marrero JA, Rudolph L, Reddy KR: Diagnosis and treatment of hepatocellular carcinoma. Gastroenterology 2008, 134:1752-1763.

36. Janke J, Schlüter K, Jandrig B, Theile M, Kölble K, Arnold W, Grinstein E, Schwartz A, Estevéz-Schwarz L, Schlag PM, Jockusch BM, Scherneck S: Suppression of tumorigenicity in breast cancer cells by the microfilament protein profilin 1. JExp Med 2000, 191:1675-1686

37. Wu N, Zhang W, Yang Y, Liang Y, Wang L, Jin J, Cai X, Zha X: Profilin 1 obtained by proteomic analysis in all-trans retinoic acid-treated hepatocarcinoma cell lines is involved in inhibition of cell proliferation and migration. Proteomics 2006, 6:6095-6106.

38. Rigden DJ, Bagyan I, Lamani E, Setlow P, Jedrzejas MJ: A cofactordependent phosphoglycerate mutase homolog from Bacillus stearothermophilus is actually a broad specificity phosphatase. Protein Sci 2001, 10:1835-1846. 
39. Fraser $\mathrm{HI}$, Kvaratskhelia M, White MF: The two analogous phosphoglycerate mutases of Escherichia coli . FEBS Lett 1999, 455:344-348,

40. Rafael MS, Encalada R, Alvaro MH, Saavedra E: Experimental validation of metabolic pathway modeling an illustration with glycolytic segments from Entamoeba histolytica. FEBS J 2008, 275:3454-3469.

41. Gonzalez-Cinca N, Pérez de la Ossa P, Carreras J, Climent F: Effects of thyroid hormone and hypoxia on 2,3-Bisphosphoglycerate, bisphosphoglycerate synthase and phosphoglycerate mutase in rabbit erythroblasts and reticulocytes in vivo. Horm Res 2004, 62:191-196.

42. Hamaguchi T, lizuka N, Tsunedomi R, Hamamoto Y, Miyamoto T, lida M, Tokuhisa Y, Sakamoto K, Takashima M, Tamesa T, Oka M: Glycolysis module activated by hypoxia-inducible factor 1 alpha is related to the aggressive phenotype of hepatocellular carcinoma. Int J Oncol 2008, 33:725-731.

43. Gatenby RA, Gillies RJ: Why do cancers have high aerobic glycolysis? Nat Rev Cancer 2004, 4:891-899.

44. Liu R, Li Z, Bai S, Zhang H, Tang M, Lei Y, Chen L, Liang S, Zhao Y, Wei Y, Huang C: Mechanism of cancer cell adaptation to metabolic stress: proteomics identification of a novel thyroid hormone mediated gastric carcinogenic signaling pathway. Mol Cell Proteomics 2009, 8:70-85.

45. McFate T, Mohyeldin A, Lu H, Thakar J, Henriques J, Halim ND, Wu H, Schell MJ, Tsang TM, Teahan O, Zhou S, Califano JA, Jeoung NH, Harris RA, Verma A: Pyruvate dehydrogenase complex activity controls metabolic and malignant phenotype in cancer cells. J Biol Chem 2008, 283:22700-22708.

46. Ortega AD, Sánchez-Aragó M, Giner-Sánchez D, Sánchez-Cenizo L, Willers I, Cuezva JM: Glucose avidity of carcinomas. Cancer Lett 2009, 276:125-135

47. Mashima T, Seimiya H, Tsuruo T: De novo fatty-acid synthesis and related pathways as molecular targets for cancer therapy. Br J Cancer 2009, 100:1369-1372.

48. Viollet B, Athea Y, Mounier R, Guigas B, Zarrinpashneh E, Horman S, Lantier L, Hebrard S, Devin-Leclerc J, Beauloye C, Foretz M, Andreelli F, VenturaClapier R, Bertrand L: AMPK: Lessons from transgenic and knockout animals. Front Biosci 2009, 14:19-44.

49. Board M, Humm S, Newsholme EA: Maximum activities of key enzymes of glycolysis, glutaminolysis, pentose phosphate pathway and tricarboxylic acid cycle in normal, neoplastic and suppressed cells. Biochem J 1990, 265:503-509.

50. Gillies RJ, Gatenby RA: Adaptive landscapes and emergent phenotypes: why do cancers have high glycolysis? J Bioenerg Biomembr 2007, 39:251-257.

51. Ko YH, Pedersen PL, Geschwind JF: Glucose catabolism in the rabbit VX2 tumor model for liver cancer: characterization and targeting hexokinase. Cancer Lett 2001, 173:83-91.

52. Hanahan D, Weinberg RA: The hallmarks of cancer. Cell 2000, 100:57-70.

53. Kasibhatla S, Tseng B: Why target apoptosis in cancer treatment? Mol Cancer Ther 2003, 2:573-580

54. Kok JW, Sietsma H: Sphingolipid metabolism enzymes as targets for anticancer therapy. Curr Drug Targets 2004, 5:375-82.

55. Chi JT, Chang HY, Wang NN, Chang DS, Dunphy N, Brown PO: Genomewide view of gene silencing by small interfering RNAs. Proc Natl Acad Sci USA 2003, 100:6343-6.

\section{Submit your next manuscript to BioMed Central} and take full advantage of:

- Convenient online submission

- Thorough peer review

- No space constraints or color figure charges

- Immediate publication on acceptance

- Inclusion in PubMed, CAS, Scopus and Google Scholar

- Research which is freely available for redistribution

Submit your manuscript at www.biomedcentral.com/submit
C) Biomed Central 